CUAD. CONTAB. / BOGOTÁ, COLOMBIA, 16 (42): 689-712 / SEPTIEMBRE-DICIEMBRE 2015 / 689

\title{
La prueba pericial contable especializada en los delitos económicos y financieros: análisis del caso DMG*
}

doi:10.11144/Javeriana.cc16-42.ppce

\author{
Maricela Ramírez \\ Docente investigadora de la Universidad Pedagógica y \\ Tecnológica de Colombia. Magíster en administración \\ económica y financiera, especialista en revisoría fiscal, \\ contadora pública con experiencia en el sector público. \\ Correo electrónico: maricela.ramirez@uptc.edu.co
}

\section{Natalia Robayo-Nieto}

Contadora Pública. Joven investigadora del grupo de investigación GIDICON. Universidad Pedagógica y Tecnológica de Colombia.

Correo electrónico: natalia.robayo@uptc.edu.co

\section{Lina María Parra-Castiblanco}

Contadora pública. Especialista en gerencia tributaria. Joven investigadora del grupo GIDICON. Universidad Pedagógica y Tecnológica de Colombia.

Correo electrónico: linamaria.parra@uptc.edu.co

\footnotetext{
* El artículo se deriva de la investigación denominada El nuevo sistema penal acusatorio y la prueba pericial contable especializada, cuyo objetivo principal es determinar las características de la prueba pericial contable especializada en el marco del nuevo sistema penal acusatorio. En este caso, se toma como referente DMG Grupo Holding S.A.
} 
Resumen En los delitos de orden económico y financiero tipificados en el Código Penal, por lo general es necesaria la actuación de peritos contables como auxiliares de la justicia. De esta manera, el profesional designado elabora un informe pericial de su trabajo de análisis e investigación de evidencia y comparece en el juicio oral y público para que pueda ser interrogado y contrainterrogado.

En este contexto, el presente estudio derivado de actividades formales de investigación determinará los requerimientos de la prueba pericial contable especializada en los delitos económicos y financieros en Colombia; toma como referente el caso del DMG Grupo Holding S.A., cuyo mayor accionista David Eduardo Helmunt Murcia-Guzmán fue condenado por los delitos de lavado de activos agravado y captación masiva habitual de dinero.

Para lograrlo, esta investigación pretende establecer los requerimientos legales de la prueba pericial contable especializada; analizar la sentencia del caso DMG, determinando las características y el aporte de las pruebas; y, por último, definir los lineamientos para el manejo de la prueba pericial en los delitos económicos y financieros bajo el sistema penal acusatorio colombiano.

El caso de estudio (DMG Grupo Holding S.A.) introduce en el juicio oral y público, más de 100 pruebas como medio para reafirmar los delitos que se estaban imputando, situación que demanda la participación de varios peritos contables adscritos a entidades oficiales.

Palabras clave Prueba pericial contable; sistema penal acusatorio; delitos económicos y financieros

Código JEL M42

\section{Specialized Accounting Expert Evidence on Economic and Financial Crimes: Analysis of the DMG Case}

Abstract Generally, in the cases related to economic and financial fraud crimes defined in the Code of Criminal Procedure the performance of accounting experts is necessary, as to assist the justice system. Thus, the appointed professional creates an expert report of its evidence analysis and research work, and comes before the court in a public oral trial as to be questioned and cross-examined.

In this context, this study -derived from formal research activities- will determine the requirements of the accounting expert assessment specialized on economic and financial crimes in Colombia. We use for reference purposes the DMG Grupo Holding S.A. case, whose majority stockholder, David Eduardo Helmunt Murcia-Guzman, was convicted for aggravated money laundering and regular mass acquisition of money.

To achieve said purpose, this research aims to establish the legal requirements of the specialized expert accounting evidence; analyze the ruling of the DMG case, determining the characteristics and contribution of the evidence; and, lastly, define the guidelines to handle the expert evidence for economic and financial crimes under the Colombian adversarial criminal justice system.

The case under study (DMG Grupo Holding S.A.) brings to the public oral trial over 100 pieces of evidence to reaffirm the crimes being attributed, which required the participation of several accounting expects affiliated to government entities.

Keywords accounting expert evidence; adversarial criminal justice system; economic and financial crimes.

\section{A prova pericial contábil especializada nos crimes econômicos e financeiros: análise do caso DMC}

Resumo Nos crimes de ordem econômica e financeira tipificados no Código Penal, pelo geral, é precisa a atuação de peritos contábeis como auxiliares da justiça. Assim, o profissional designado elabora um relatório pericial do seu trabalho de análise e pesquisa de evidência e comparece no julgamento oral e público para puder ser inquerido e contrainquerido.

Neste contexto, o presente estudo derivado de atividades formais de pesquisa vai determinar os requerimentos da 
prova pericial contábil especializada em crimes económicos e financeiros na Colômbia; tem como referente o caso de DMG Grupo Holding S.A., cujo principal acionista David Eduardo Helmunt Murcia-Guzmán foi condenado pelos crimes de lavagem de ativos agravada e captação massiva habitual de dinheiro.

Para conseguir, esta pesquisa visa estabelecer os requerimentos legais da prova pericial contábil especializada; analisar a sentença do caso DMG, a determinar as características e contribuição das provas; e, por fim, definir as diretrizes para a manipulação da prova pericial nos delitos econômicos e financeiros sob o sistema penal acusatório colombiano.

O caso de estudo (DMG Grupo Holding S.A.) introduz no juízo oral e público mais de 100 provas como médio para reafirmar os crimes que se estavam imputando, situação que demanda a participação de vários peritos contábeis adscritos a instituições oficiais.

Palavras-chave Prova pericial contábil; sistema penal acusatório; crimes econômicos e financeiros.

\section{Introducción}

La prueba pericial, como uno de los tipos de prueba contemplados en el Código de Procedimiento Penal, CPP, actúa como medio probatorio adecuado y oportuno en aquellos casos en que se requieren conocimientos que no posee el fallador y, por tanto, necesita recurrir a expertos que, por su formación y experiencia en las diferentes ciencias, técnicas o artes, puedan lograr a partir de sus informaciones u opiniones fundadas una apreciación más clara de los hechos en cuestión.

El contador público como auxiliar de la justicia es el profesional encargado de allegar ante el tribunal de la justicia la prueba pericial con- table especializada; esta función, además del conocimiento relacionado con el proceso contable y financiero, le demanda el cumplimiento de los requisitos legales vinculados al derecho probatorio bajo las características del nuevo sistema penal acusatorio.

En este escenario, el presente estudio abordará los requerimientos de la prueba pericial contable especializada en los delitos económicos y financieros en el marco del sistema penal actual y tomará como caso de estudio el del DMG Grupo Holding S.A.

\section{Metodología}

A partir de un estudio de caso representativo en el ámbito nacional, se aborda el tema de investigación. El procedimiento lógico y riguroso que orienta la investigación se basa en el método inductivo desde el cual se proyecta obtener las generalidades aplicables a la prueba pericial contable en los delitos económicos y financieros desde las fuentes de investigación consultadas y analizadas. El proceso judicial objeto de estudio es seleccionado por el modus operandi de los implicados y por la dimensión económica y social que lo caracteriza.

\section{Resultados}

\section{La prueba pericial contable especializada en los delitos económicos y financieros en Colombia}

\section{La prueba judicial}

En la noción de prueba, el sustantivo se deriva del verbo probar que equivale a buscar, indagar, 
averiguar, experimentar, ensayar, investigar, contrastar acerca de la posibilidad de un hecho o de una cosa, para tener de él o de ella una representación o un juicio que corresponda a la realidad y así pueda llamarse verdadero (Borja-Niño, 2003, p. 78). Esta definición permite dimensionar las implicaciones del término probar al relacionarlo con la búsqueda de la verdad.

Ahora, desde el punto de vista legal, probar judicialmente implica hacerle conocer al juez los hechos controvertidos y dudosos y darle certeza sobre su forma de ser (Lessona, 1964, p. 46). Si bien la idea de la cosa se tiene y adquiere por el raciocinio, por los sentidos de quien juzga y por las referencias de los demás, es necesario un vehículo, un medio que relacione a la cosa con la idea, y ese medio es la prueba (Rocha, 1967, p. 121).

De esta manera, la prueba brinda una percepción orientadora al juez de lo que ve o examina directamente, si escucha una grabación o ve un documento tiene una percepción visual e imaginativa de lo que en este se representa; luego, para conocer un suceso, el juez necesita primero una percepción sensorial y seguidamente un proceso que le permita obtener una conclusión, a partir de la prueba.

\section{La prueba en el sistema penal colombiano}

El manejo de la prueba en Colombia se desarrolla en torno a las características del sistema penal acusatorio, el cual - a partir de la Ley 906 de 2004, Código de Procedimiento Penal, $\mathrm{CPP}$ - contempla las normas de procedimiento aplicables al trámite de las investigaciones y los juicios por parte de la Fiscalía General de la Nación, los jueces y los tribunales.

El concepto de prueba, introducido en el Acto Legislativo 03 de 2002, reforma el artículo 250 de la Constitución Nacional y marca el cambio del sistema procesal penal, con el principio de inmediación de la prueba en el que expresa que "en el juicio únicamente se estimará como prueba la que haya sido producida o incorporada en forma oral, concentrada, y sujeta a confrontación y contradicción ante el juez de conocimiento" (Art. 16 CPP).

De esta manera, los actos de la investigación en el actual sistema penal se desarrollan de la siguiente manera:
Informada la Fiscalía General de la Nación de la noticia criminal, la actividad que se de- sarrolla a partir de allí busca la consecución de los medios de conocimiento que luego puedan ser aducidos en el juicio, que sirvan como prueba de la ocurrencia del hecho pre- visto en la ley como delito y de su autoría por parte de la persona en cuya contra luego se habrá de formular imputación y posterior- mente acusación, y para cuya validez debe garantizarse su inalterabilidad durante todo el tiempo, mediante la cadena de custodia (Restrepo-Medina, 2005, p. 37).

Como se afirma, los medios de conocimiento le permiten a la Fiscalía establecer que ha ocurrido un delito e identificar a las personas que lo han causado o que han intervenido o determinado su realización. El Código de Procedimiento Penal señala como medios de conocimiento: "los elementos materiales pro- 
batorios, la evidencia física, la prueba testimonial, la prueba pericial, la prueba documental, la prueba de inspección, o cualquier otro medio técnico o científico, que no viole el ordenamiento jurídico" (Art. 382 CPP).

\section{Medios de conocimiento: evidencia física y elemento material probatorio}

La evidencia física y el elemento material probatorio se definen como: "cualquier objeto relacionado con una conducta punible, que pueda servir para determinar la verdad en una actuación penal" (Fiscalía General de la Nación, Consejo Nacional de Policía Judicial, s.f., p. 59). No obstante, el Código de Procedimiento Penal, aunque no define taxativamente estos conceptos, sí establece los siguientes elementos materiales probatorios y evidencia física (Art. 275 CPP):

a. Huellas, rastros, manchas, residuos, vestigios y similares, dejados por la ejecución de la actividad delictiva.

b. Armas, instrumentos, objetos y cualquier otro medio utilizado para la ejecución de la actividad delictiva.

c. Dinero, bienes y otros efectos provenientes de la ejecución de la actividad delictiva.

d. Los elementos materiales descubiertos, recogidos y asegurados en desarrollo de diligencia investigativa de registro y allanamiento, inspección corporal y registro personal.

e. Los documentos de toda índole hallados en diligencia investigativa de inspección o que han sido entregados voluntaria- mente por quien los tenía en su poder o que han sido abandonados allí.

f. Los elementos materiales obtenidos mediante grabación, filmación, fotografía, video o cualquier otro medio avanzado, utilizados como cámaras de vigilancia, en recinto cerrado o en espacio público.

g. El mensaje de datos, como el intercambio electrónico de datos, internet, correo electrónico, telegrama, télex, telefax o similar, regulados por la Ley 527 de 1999 o las normas que la sustituyan, adicionen o reformen.

h. Los demás elementos materiales similares a los anteriores y que son descubiertos, recogidos y custodiados por el Fiscal General o por el fiscal directamente o por conducto de servidores de policía judicial o de peritos del Instituto Nacional de Medicina Legal y Ciencias Forenses, o de laboratorios aceptados oficialmente.

Esta evidencia y el elemento material probatorio pueden convertirse en prueba si se incorporan en el juicio y cumplen los tres criterios de valoración: legalidad, autenticidad e identificación técnica científica (ver tabla 1)

En el sistema penal la evidencia física "es más confiable y objetiva que la prueba testimonial, y el desarrollo de la ciencia la ha hecho más importante" (Restrepo-Medina, 2005, p. 39). 


\begin{tabular}{|c|c|c|}
\hline $\begin{array}{c}\text { Legalidad } \\
\text { (Art. } 276 \text { CPP) }\end{array}$ & $\begin{array}{l}\text { Autenticidad } \\
\text { (Art. } 277 \text { CPP) }\end{array}$ & $\begin{array}{c}\text { Identificación técnico } \\
\text { científica } \\
\text { (Art. 278 CPP) }\end{array}$ \\
\hline $\begin{array}{l}\text { La legalidad del elemento material } \\
\text { probatorio y evidencia depende } \\
\text { de que en la diligencia en la } \\
\text { cual se recoge o se obtiene, se } \\
\text { haya observado lo prescrito en } \\
\text { la Constitución Política, en los } \\
\text { Tratados Internacionales sobre } \\
\text { derechos humanos vigentes en } \\
\text { Colombia y en las leyes. }\end{array}$ & $\begin{array}{l}\text { Los elementos materiales probatorios y la } \\
\text { evidencia física son auténticos cuando han } \\
\text { sido detectados, fijados, recogidos y embalados } \\
\text { técnicamente, y sometidos a las reglas de cadena } \\
\text { de custodia. } \\
\text { La demostración de la autenticidad de los } \\
\text { elementos materiales probatorios y evidencia } \\
\text { física no sometidos a cadena de custodia, estará a } \\
\text { cargo de la parte que los presente. }\end{array}$ & $\begin{array}{l}\text { La identificación técnico } \\
\text { científica consiste en la } \\
\text { determinación de la naturaleza } \\
\text { y características del elemento } \\
\text { material probatorio y evidencia } \\
\text { física, hecha por expertos en } \\
\text { ciencia, técnica o arte. Dicha } \\
\text { determinación se expondrá en el } \\
\text { informe pericial. }\end{array}$ \\
\hline
\end{tabular}

Tabla 1

Criterios de valoración de la evidencia y elemento material probatorio

Fuente: elaboración propia con base en el Código de Procedimiento Penal

\section{La cadena de custodia de los elementos materiales probatorios y la evidencia}

\section{física}

La valoración de los elementos materiales probatorios y de la evidencia física se hará teniendo en cuenta — además de su legalidad, autenticidad y grado actual de aceptación científica técnicael sometimiento a cadena de custodia (Art. 273 CPP). De esta manera, en su Resolución 2869 de 2003, la Fiscalía General de la Nación define la cadena de custodia como el procedimiento empleado para asegurar y demostrar la autenticidad de los elementos materiales probatorios y la evidencia física; de tal forma que desde su descubrimiento hasta su admisión como prueba, se pueda establecer su identidad, estado original, condiciones de recolección, preservación, embalaje y envío, lugares y fechas de permanencia y cambios realizados por cada custodio, así como el nombre y la identificación de todas las personas que hayan estado en contacto con los elementos.

La cadena de custodia se inicia en el lugar donde se descubran, recauden o encuentren los elementos materiales probatorios y la evidencia física, y finaliza por orden de la autoridad competente, y entre ambos extremos su aplicación es responsabilidad de los servidores públicos que entren en contacto con los mismos.

\section{De la evidencia a la prueba}

Como se ha mencionado, la evidencia es cualquier objeto relacionado con una conducta punible que puede servir para determinar las circunstancias reales de tiempo, modo y lugar en las que el hecho se realizó y que deberá someterse al régimen de cadena de custodia. Mientras tanto la prueba es considerada como aquel elemento que, una vez hace parte de un proceso judicial, pretende hacer llegar al convencimiento acerca de la certeza de la existencia u ocurrencia de un determinado hecho (Juzgado Cuarto Penal del Circuito Especializado de Conocimiento de Bogotá, 2009).

Ahora bien, se puede aducir que la evidencia dentro del proceso judicial está presente en la etapa de indagación e investigación; no obstante, la prueba se incorpora hasta en el juicio a partir de la audiencia de formulación de acusación, como lo ilustra la figura 1. 


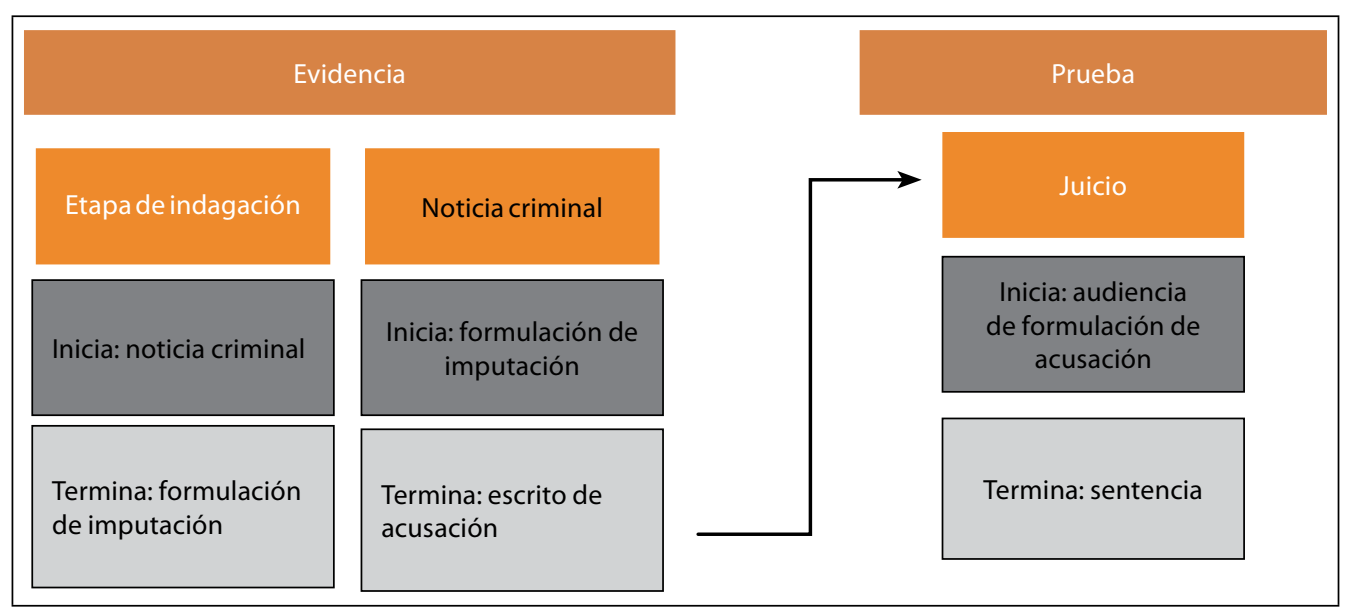

Figura 1

Evidencia y prueba en el sistema penal acusatorio

Fuente: elaborado con base en Pedro Oriol Avella-Franco (2007). Estructura del proceso penal acusatorio

Practicada la prueba, las partes tienen la facultad de controvertirla, tanto si se ha presentado en el juicio, como si se ha practicado por fuera de la audiencia pública; para que las pruebas puedan ser tenidas en cuenta por el juez, deben practicarse y controvertirse en su presencia.

\section{La prueba pericial: otro medio de conocimiento}

La prueba pericial ha sido definida como aquella que se realiza para aportar al proceso las máximas de la experiencia que el juez no posee o no puede poseer y para facilitar la percepción y la apreciación de los hechos concretos objeto del debate (Climent-Durán, 1999, p. 54).

Asimismo, "la prueba pericial se constituye en un medio probatorio indirecto, histórico, ya que los datos que proporciona son mediatos y representativos con relación a los hechos a probar. Utiliza a personas que deben revestir la calidad de terceros, poseer conocimientos especiales en cuanto a la comprobación del hecho, causa o efecto" (Varela, 1990, p. 191).

Legalmente, este tipo de prueba consiste en valoraciones que requieran conocimientos científicos, técnicos o especializados (Art. 405 CPP), efectuadas por los expertos de la policía judicial, del Instituto Nacional de Medicina Legal y Ciencias Forenses, entidades públicas o privadas y particulares especializados en la materia de que se trate. Las investigaciones o análisis deben ser realizados por el perito o los peritos, según el caso, quienes deben suscribir el correspondiente informe bajo la gravedad del juramento (Art. $406 \mathrm{CPP}$ ).

Es evidente que los peritos revisten el carácter de auxiliares de la justicia, pero esto no descarta la índole probatoria de la pericia, que constituye un verdadero medio probatorio, al explicar datos que aporten para la formación de una determinada convicción acerca de la existencia o inexistencia de los hechos controverti- 
dos en el proceso. El artículo 236 del Código de Procedimiento Civil regula lo referente a la petición de la prueba y posesión de los peritos.

Según la Sentencia T-288-11 de la Corte Constitucional, quien emite el informe no expresa hechos, sino conceptos técnicos relevantes en el proceso; expresa conceptos cualificados de expertos en materias científicas, técnicas o artísticas, pero bajo ningún punto sobre aspectos jurídicos, no obstante se practica por encargo judicial previo.

En Colombia, para poder ser perito se requiere tener un título legalmente reconocido en la respectiva ciencia, técnica o arte, o, en circunstancias diferentes tener reconocido entendimiento en la respectiva ciencia, técnica, arte, oficio o afición, aunque se carezca de título; para acreditar el conocimiento son admisibles todos los medios de prueba, incluyendo el propio testimonio del declarante que se presenta como perito (Art. $408 \mathrm{CPP}$ ).

\section{La prueba pericial contable especializada}

La prueba pericial y su objeto obedecen a un programa metodológico liderado por la autoridad judicial. Aquí, el contador público actúa como auxiliar de la justicia en los casos en que señala la ley, como perito expresamente designado para ello. Se espera — según la Ley 43 de $1990^{1}$ — que en esta condición, el

1 Ley 43 de 1990, por la cual se adiciona la Ley 145 de 1960, reglamentaria de la profesión de contador público y se dictan otras disposiciones. Diario Oficial, 39.602, 13 de diciembre de 1990. Disponible en: https://www. cancilleria.gov.co/sites/default/files/Normograma/docs/ ley_0043_1990.htm contador público cumpla su deber teniendo las más altas miras de su profesión, la importancia de la tarea que la sociedad le encomienda como experto y la búsqueda de la verdad en forma totalmente objetiva (Colombia, 1990).

De esta manera, se requiere la participación del perito contable, como apoyo a la Fiscalía General de la Nación en el estrado judicial mediante la exposición profesional de los hallazgos de evidencias establecidas de su acuciosa labor de auditoría aplicada a los documentos, elementos materiales de prueba, recolectados en el desarrollo de la investigación.

La experticia en este caso consiste en el manejo de las técnicas que soportan la contabilidad en Colombia; si se trata de información preparada bajo Principios de Contabilidad Generalmente Aceptados, se debe evaluar el cumplimiento de los requerimientos estipulados en los Decretos 2649 y 2650 de 1993 y los demás lineamientos técnicos obligatorios expedidos desde los diferentes entes de control y vigilancia.

Asimismo, si se trata de información contable preparada bajo las Normas Internacionales de Información (NIIF) se debe observar el cumplimiento de estos estándares en el reconocimiento, medición, presentación y revelación en la preparación de los estados financieros.

\section{De los delitos económicos y financieros}

La actuación del profesional de la contaduría pública como perito y auxiliar de la justicia se relaciona con los delitos económicos y financieros, los cuales están estipulados en la Ley 599 de 2000, Código Penal (CP), así: 


\begin{tabular}{ll}
\hline $\begin{array}{l}\text { Delitos contra el orden económico social } \\
\text { (Título X CP) }\end{array}$ & $\begin{array}{l}\text { El acaparamiento, la especulación y otras infracciones, delitos contra el } \\
\text { sistema financiero, urbanización ilegal, contrabando y lavado de activos } \\
(\text { Capítulos I-V). }\end{array}$ \\
$\begin{array}{l}\text { Delitos contra el patrimonio económico } \\
\text { (Título VII CP) }\end{array}$ & $\begin{array}{l}\text { Hurto, extorsión, estafa, fraude mediante cheque, del abuso de confianza, } \\
\text { defraudaciones, usurpación, daño en bien ajeno (Capítulos I-IX). }\end{array}$ \\
Delitos contra la administración pública & $\begin{array}{l}\text { Peculado, concusión, cohecho, celebración indebida de contratos, tráfico de } \\
\text { influencias, enriquecimiento ilícito, prevaricato, abuso de autoridad, delitos }\end{array}$ \\
& contra los empleados oficiales (Capítulos I-X). \\
\hline
\end{tabular}

Tabla 2

Delitos económicos y financieros en Colombia

Fuente: elaboración propia con base en Código Penal colombiano

El perito contable encargado de elaborar el dictamen pericial en este tipo de ilícitos se enfrenta en especial a pruebas documentales tomadas de bases de datos o inspecciones judiciales de acuerdo con la urgencia de la indagación y con las políticas institucionales de la Fiscalía.

En la mayoría de los casos, los documentos de este tipo son obtenidos por la policía judicial en colaboración institucional con entidades como la Dirección de Impuestos y Aduanas Nacionales, DIAN; las empresas promotoras de salud, EPS; las entidades bancarias; la Unidad de Información y Análisis Financiero, UIAF; el Banco de la República; la Registraduría Nacional del Estado Civil; las Cámaras de Comercio; y el Depósito Centralizado de Valores de Colombia, DECEVAL S.A., entre otras.

Se espera igualmente que, a partir de su experticia, el perito analice estos materiales probatorios y evidencias para generar un informe pericial que determine su grado de cumplimiento de la legislación contable, fiscal, estatutaria y demás normatividad que le sea aplicable en cada caso.

\section{La prueba pericial contable en el caso DMG Grupo Holding S.A.}

Después de haber presentado en el marco del sistema penal acusatorio el tránsito de la evidencia y del elemento material probatorio hasta convertirlos en prueba pericial contable, se ilustra a continuación el proceso judicial en el caso del DMG Grupo Holding S.A.

Como lo ilustra la figura 2, el caso del DMG Grupo Holding S.A. en el sistema penal acusatorio presentó las siguientes etapas:

a. En la etapa de indagación, conocida la noticia criminal, con base en el programa metodológico elaborado por el fiscal, la policía judicial se encargó de recolectar y asegurar los elementos materiales probatorios y la evidencia física necesarios. La primera intervención de los peritos contables se realizó en esta etapa, su función consistió en evaluar los elementos materiales probatorios y entregar su informe pericial.

b. En la etapa de investigación, se inició la formulación de imputación y la policía judicial, bajo la dirección del fiscal, complementó los elementos materiales probatorios y la evidencia física. 


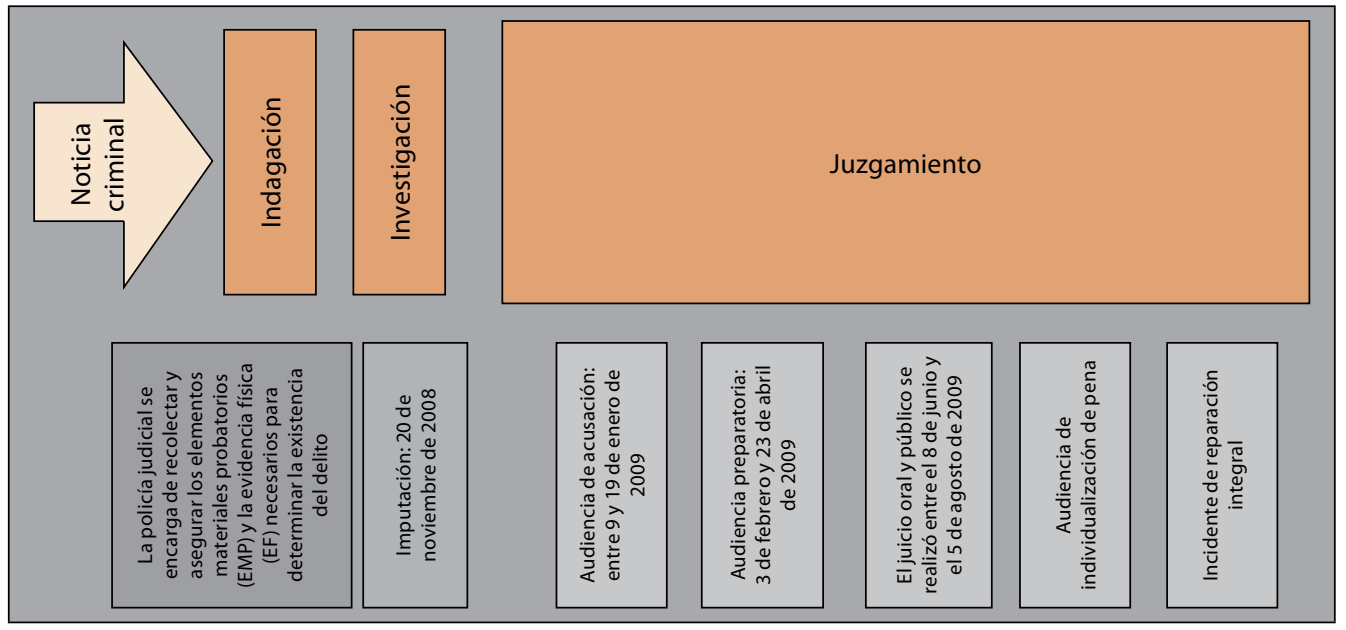

Figura 2

Proceso judicial del DMG Grupo Holding S.A., desde el sistema general penal acusatorio Fuente: elaboración propia con base en documento de Comisión Intersectorial para el Seguimiento de Sistema Penal Acusatorio, CISPA (2011)

c. En la etapa de juzgamiento, con base en los elementos materiales probatorios y la evidencia física recaudadas, se determinó en este caso que existía responsabilidad penal del acusado. Se llevaron a cabo las siguientes audiencias:

- Audiencia de formulación de acusación: es la audiencia oral realizada ante el juez de conocimiento en la que el fiscal hace un recuento de los hechos por los cuales el acusado será llevado a juicio, tiene lugar el descubrimiento de los elementos materiales probatorios recolectados por la Fiscalía y de aquellos que la defensa pretenda hacer valer en el juicio oral.

- Audiencia preparatoria: las partes enuncian la totalidad de las pruebas que pretenden hacer valer en el juicio y hacen las estipulaciones probatorias de ser estas convenidas. Con base en esto, el juez decreta las pruebas y fija la fecha para la audiencia de juicio oral.
- Juicio oral: es la audiencia pública en la que la Fiscalía expone su teoría del caso, y sus alegatos finales; también se oye a la defensa, la víctima y el Ministerio Público; finalmente, el juez emite el sentido de fallo. En esta etapa, el perito contable expone su informe pericial siendo interrogado y contrainterrogado.

- Audiencia de reparación integral: el acusado llega a un acuerdo con las partes afectadas.

La sentencia objeto de estudio le atribuye al señor David Eduardo Helmunt MurciaGuzmán los delitos de captación masiva y habitual de dinero y lavado de activos. Las pruebas que acompañan esta sentencia ascienden a 107. Desde el punto de vista fáctico, la sentencia está compuesta por 26 proposiciones jurídicamente relevantes, dadas en cuatro momentos, así: 
LA PRUeba PERICIAL CONTABle ESPECIALIzAda / M. RAMÍrez, N. Robayo, L. PARRA / 699

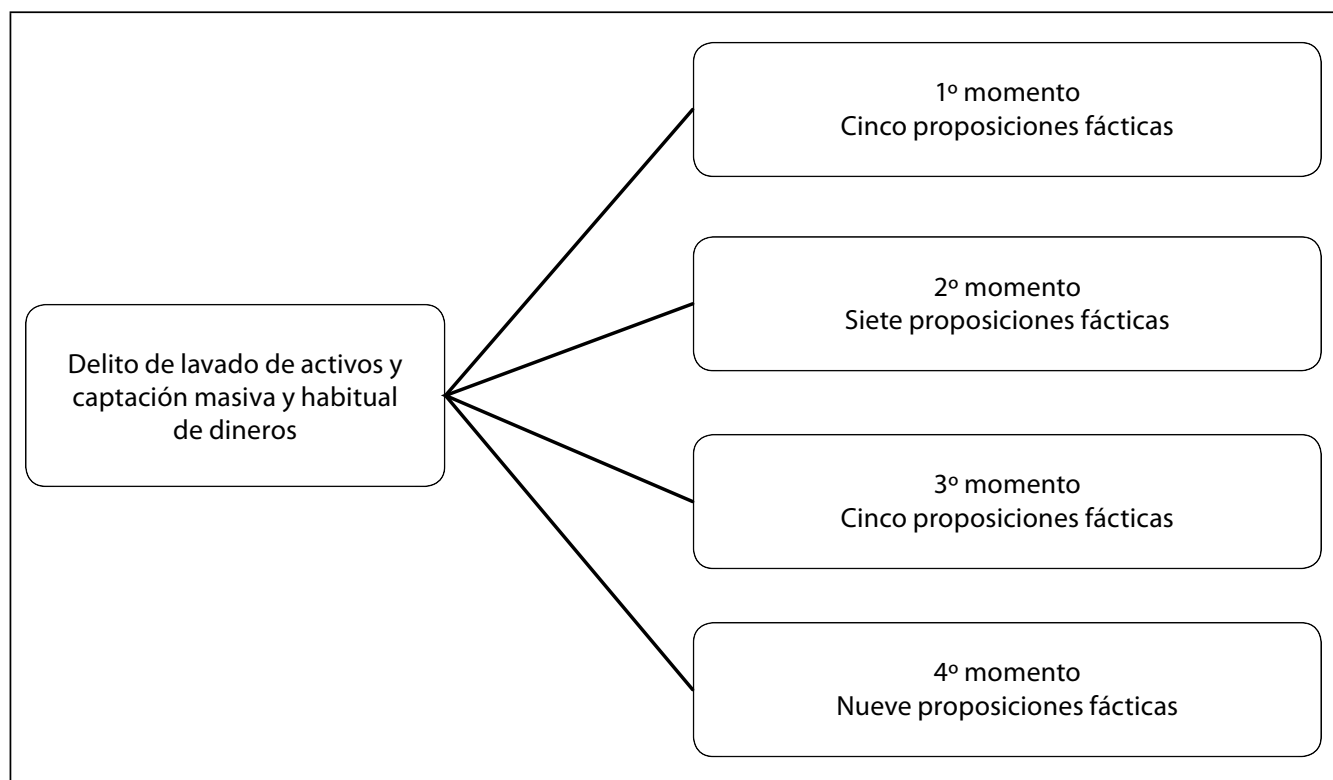

Figura 3

Momentos y proposiciones fácticas de la sentencia

Fuente: elaborado con base en Juzgado Cuarto Penal del Circuito Especializado de Conocimiento de Bogotá (2009). Sentencia 19 contra David Murcia-Guzmán, Proceso 110016000020080790

A continuación, se presentan las proposiciones fácticas de cada momento y se señalan únicamente las pruebas contables que sustentan la decisión del juez.

Primer momento. Proposiciones sustentadas con pruebas periciales contables

Proposición fáctica $1 \quad$ Materia de estipulación
y 2

\begin{tabular}{|c|c|c|}
\hline Proposición fáctica 3 & Pruebas & Peritos \\
\hline El 5 de diciembre de 2005 & Certificado de existencia y & -Perito contador Diego Javier Urrutia- \\
\hline sin que la sociedad haya & representación de la empresa Grupo & Sanabria \\
\hline desarrollado su objeto social ni & DMG S.A. & -Peritos contadores de la \\
\hline generara ingresos operacionales & Movimientos y extractos de cuentas & Superintendencia de Sociedades: Aida \\
\hline o no operacionales, recibió & bancarias & Tamayo-Rodríguez y Andrea Medina- \\
\hline de los socios en calidad de & Informe de la Superintendencia & Rojas \\
\hline préstamo una inyección & Financiera & Perito contadora Alexandra Montaña- \\
\hline de capital que ascendió a & Declaración de renta de David Murcia & Herrera, adscrita a la Dirección de \\
\hline$\$ 2.696$ '230.029, de los cuales & Documentos de Cámara de Comercio & Impuestos y Aduanas Nacionales, \\
\hline David Eduardo Helmunt & Perfil económico y tributario de David & DIAN \\
\hline Murcia-Guzmán prestó & Murcia & \\
\hline$\$ 1.135 ’ 390.320$ & & \\
\hline
\end{tabular}




\begin{tabular}{|c|c|c|}
\hline \multicolumn{3}{|c|}{ Primer momento. Proposiciones sustentadas con pruebas periciales contables } \\
\hline $\begin{array}{c}\text { Proposición fáctica } 1 \\
\text { y } 2\end{array}$ & Materia de estipulación & \\
\hline Proposición fáctica 4 & Pruebas & Peritos \\
\hline $\begin{array}{l}\text { Los préstamos efectuados por } \\
\text { los socios fueron recibidos por } \\
\text { medio de la cuenta 3-0360- } \\
\text { 000070-5 del Banco Agrario, } \\
\text { por consignaciones en efectivo, } \\
\text { fraccionadamente y cifras } \\
\text { cerradas en pesos, desde } \\
\text { localidades como Puerto Asís, } \\
\text { Mocoa, Orito, La Hormiga, } \\
\text { Montelíbano y Montería }\end{array}$ & $\begin{array}{l}\text { Declaración de renta del señor David } \\
\text { Murcia, correspondiente al año } 2005 \\
\text { Certificaciones de afiliación y rango } \\
\text { salarial de las empresas promotoras } \\
\text { de salud Colmédica y Salud Total, } \\
\text { correspondientes al señor David Murcia } \\
\text { Perfil tributario correspondiente al } \\
\text { señor David Murcia }\end{array}$ & $\begin{array}{l}\text { Perito contador Diego Javier Urrutia- } \\
\text { Sanabria }\end{array}$ \\
\hline Proposición fáctica 5 & Pruebas & Peritos \\
\hline $\begin{array}{l}\text { Los socios, entre ellos David } \\
\text { Eduardo Helmunt Murcia- } \\
\text { Guzmán, no tenían actividad } \\
\text { económica en los lugares de } \\
\text { donde provenían los recursos } \\
\text { y carecían de capacidad } \\
\text { económica, primero para } \\
\text { constituir la sociedad y luego } \\
\text { para inyectar el citado capital, } \\
\text { siendo ilícito ese dinero }\end{array}$ & $\begin{array}{l}\text { Declaración de renta del señor David } \\
\text { Murcia, correspondiente al año } 2005 \\
\text { Certificaciones de afiliación y rango } \\
\text { salarial de las empresas promotoras } \\
\text { de salud Colmédica y Salud Total, } \\
\text { correspondientes al señor David Murcia } \\
\text { Perfil tributario correspondiente al } \\
\text { señor David Murcia }\end{array}$ & $\begin{array}{l}\text { Perito contadora Alexandra Montaña- } \\
\text { Herrera, adscrita a la Dirección de } \\
\text { Impuestos y Aduanas Nacionales, } \\
\text { DIAN }\end{array}$ \\
\hline
\end{tabular}

Tabla 3

Primer momento: proposiciones fácticas, pruebas y peritos

Fuente: elaborado con base en Juzgado Cuarto Penal del Circuito Especializado de Conocimiento de Bogotá (2009). Sentencia 19 contra David Murcia-Guzmán, Proceso 110016000020080790

Como se puede observar en este primer momento, los hechos que se estudian buscan determinar el origen de los recursos que ingresan por medio de consignaciones a las cuentas bancarias y su relación con la actividad económica del grupo empresarial. Las pruebas introducidas en el juicio oral, público y contradictorio se obtuvieron de entidades bancarias, cámaras de comercio, Dirección de Impuestos y Aduanas Nacionales, empresas promotoras de salud y superintendencias y fueron estudiadas por peritos contadores que, adicionalmente a los documentos recopilados por la policía judicial, elaboraron el perfil económico y tributario de David Murcia. 


\section{Segundo momento. Proposiciones sustentadas con pruebas periciales contables}

\section{Proposición fáctica 6}

En 2006, la sociedad Grupo DMG S.A. comenzó a captar de forma masiva y habitual, dineros del público por medio de tarjetas prepago

\section{Pruebas}

Informe del presidente del Banco Agrario en el que advierte sobre una posible

captación de dinero por parte del Grupo DMG S.A.

Estados financieros de la sociedad Grupo DMG S.A., de 2005 y 2006

Reglamento que la sociedad Grupo DMG S.A. fijó para la utilización de las tarjetas prepago
Peritos

Mauricio Ortiz-Lora (abogado experto en contabilidad y derecho económico y financiero) y Germán Antonio LeónCanchón (economista)

\begin{tabular}{|c|c|c|}
\hline Proposición fáctica 7 & Pruebas & Peritos \\
\hline & & $\begin{array}{l}\text { Investigador de la Policía } \\
\text { Nacional }\end{array}$ \\
\hline Proposición fáctica 8 & Pruebas & Peritos \\
\hline A 31 de diciembre de 2006, la sociedad & Estados financieros de la sociedad Grupo & Investigador de la Policía \\
\hline Grupo DMG S.A. había recibido la suma & DMG S.A., a 31 de diciembre de 2005 y a & Nacional Joselito Medina- \\
\hline de $\$ 13.482 ’ 000.000$, de 8.400 personas, & 31 de diciembre de 2006 & Moyano \\
\hline mediante la venta de tarjetas prepago & Soportes documentales sacados del & Peritos Mauricio Ortiz-Lora y \\
\hline \multirow[t]{2}{*}{ DMG } & libro auxiliar de la cuenta denominada & Germán Antonio León-Canchón \\
\hline & Ingresos recibidos por anticipado & \\
\hline
\end{tabular}

\section{Proposición fáctica 9}

A 31 de marzo de 2007, la sociedad mencionada había recaudado aproximadamente \$18.545'000.000, de 12.641 personas

\section{Pruebas}

\section{Peritos}

Declaración de renta del señor David Murcia, correspondiente a 2005 Certificaciones de afiliación y rango salarial de las empresas promotoras de salud Colmédica y Salud Total, correspondientes al señor David Murcia Perfil tributario correspondiente al señor David Murcia
Perito contadora Alexandra Montaña-Herrera, adscrita a la Dirección de Impuestos y Aduanas Nacionales, DIAN

Investigador de la Policía

Nacional 


\section{Segundo momento. Proposiciones sustentadas con pruebas periciales contables}

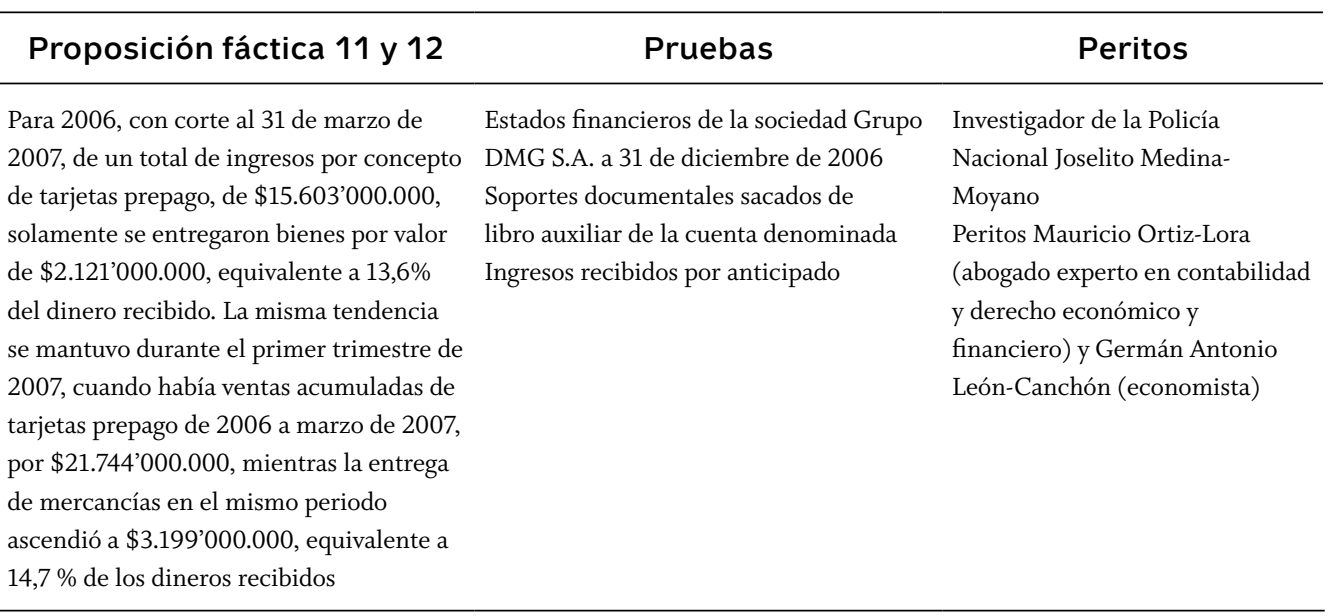

Tabla 4

Segundo momento: proposiciones fácticas, pruebas y peritos Fuente: elaborado con base en Juzgado Cuarto Penal del Circuito Especializado de Conocimiento de Bogotá (2009). Sentencia 19 contra David Murcia-Guzmán, Proceso 110016000020080790

En este segundo momento se puede observar cómo las pruebas recolectadas y estudiadas buscan la comprobación de la captación masiva y habitual de dineros del público y el modus operandi para conseguirlo. En este momento, la información financiera contenida en los libros y en los estados financieros proporciona el mayor número de pruebas. De esta forma, se evidencia cómo de las siete proposiciones fácticas únicamente la proposición siete no está representada por pruebas contables.

En el tercer momento, se presentan cinco proposiciones fácticas de las cuales tres son evaluadas por peritos contables. En este momento, se pretende comprobar la creación del DMG Grupo Holding S.A. por parte del señor Murcia-Guzmán y el modus operandi de esta entidad y sus socios.

En el cuarto momento se presentan nueve proposiciones fácticas de las cuales tan solo tres corresponden a pruebas analizadas por peritos contables y confirman cómo este tipo de ilícitos involucra toda una cadena de delitos conformados por entidades intermediarias que aparentan la circulación de dinero. Las demás pruebas que son contables se relacionan con audios de los implicados.

Como lo demuestra este proceso judicial, la contabilidad se convierte en la prueba contundente que sirve de base al juez en el momento de emitir su fallo. El fin primordial del lavado de activos es la legalización de bienes o activos o, por lo menos, la búsqueda de la apariencia de legalidad. "Para tal efecto, los lavadores acuden a la realización de operaciones financieras, ingenierías contables generalmente complejas, por medio de las cuales se intenta darle la apariencia de licitud al dinero obtenido ilegalmente" (Cano-Castaño, 2000, p. 5). 
Tercer momento. Proposiciones sustentadas con pruebas periciales contables

\begin{tabular}{|c|c|c|}
\hline Proposición fáctica 13 & Pruebas & Peritos \\
\hline $\begin{array}{l}\text { El } 7 \text { de abril de } 2006 \text {, mediante escritura } \\
\text { pública número } 1238 \text { de la Notaría } 63 \text { de } \\
\text { Bogotá, los mismos socios del Grupo DMG } \\
\text { S.A., entre ellos David Eduardo Helmunt } \\
\text { Murcia-Guzmán, crearon la empresa DMG } \\
\text { Grupo Holding S.A., con igual objeto social } \\
\text { y un capital de } \$ 250 ’ 000.000\end{array}$ & $\begin{array}{l}\text { Escrituras públicas } 1238 \text { y } 5274 \text { de } \\
\text { la Notaría } 63 \text { de Bogotá, por medio } \\
\text { de las cuales fue creada y reformada, } \\
\text { respectivamente, la sociedad DMG } \\
\text { Grupo Holding S.A. }\end{array}$ & $\begin{array}{l}\text { Investigador de la Policía } \\
\text { Nacional Joselito Medina- } \\
\text { Moyano }\end{array}$ \\
\hline Proposición fáctica 14 & Pruebas & Peritos \\
\hline $\begin{array}{l}\text { Registró un pasivo en Otras obligaciones } \\
\text { - Ingresos recibidos para terceros de } \\
\$ 42.723^{\prime} 013.690 \text { y un total en su patrimonio } \\
\text { de } \$ 248^{\prime} 587.962\end{array}$ & $\begin{array}{l}\text { Balance general de la empresa DMG } \\
\text { Grupo Holding S.A., a } 31 \text { de diciembre } \\
\text { de } 2006 \text { y } 2007 \\
\text { Papeles de trabajo anejos con la } \\
\text { contabilidad de la sociedad DMG } \\
\text { Grupo Holding S.A. }\end{array}$ & $\begin{array}{l}\text { Investigador de la Policía } \\
\text { Nacional Carlos Enrique } \\
\text { Londoño-Triana } \\
\text { Perito Mauricio Ortiz-Lora } \\
\text { (abogado experto en derecho } \\
\text { económico financiero y } \\
\text { contabilidad) }\end{array}$ \\
\hline Proposición fáctica 15 & Pruebas & Peritos \\
\hline $\begin{array}{l}\text { La empresa DMG Grupo Holding S.A. } \\
\text { reclutaba personas naturales, que accedían a } \\
\text { los servicios de las tarjetas prepago, para que } \\
\text { aparecieran como socios de las empresas por } \\
\text { ellos mismos constituidas }\end{array}$ & Audio de llamadas telefónicas. & $\begin{array}{l}\text { Investigador de la Policía } \\
\text { Nacional }\end{array}$ \\
\hline
\end{tabular}

Proposición fáctica 16

De igual manera, la comercialización de tarjetas prepago no tenía como contraprestación principal la venta de bienes o servicios, sino la captación masiva e ilegal de dineros del público

\section{Pruebas}

Acta de toma de información, que la Superintendencia de Sociedades hizo el 2 de abril de 2008, a la sociedad DMG

Grupo Holding S.A.

Papeles de trabajo anejos con la contabilidad de la sociedad DMG

Grupo Holding S.A.
Peritos

Investigadores de la Policía

Nacional Carlos Enrique

Londoño-Triana, perito Mauricio Ortiz-Lora

\begin{tabular}{lll}
\multicolumn{1}{c}{ Proposición fáctica 17 } & \multicolumn{1}{c}{ Pruebas } & \multicolumn{1}{c}{ Peritos } \\
\hline $\begin{array}{l}\text { Para el año 2007, DMG Grupo } \\
\text { HOLDING S.A., había recibido un total } \\
\text { de \$160.766'640.000 y para el año 2008 }\end{array}$ & $\begin{array}{l}\text { Informe de investigación de campo con } \\
\text { anexos. }\end{array}$ & $\begin{array}{l}\text { Aida Tamayo-Rodríguez, perito } \\
\text { administradora pública adscrita } \\
\text { \$1.043.484'917.770 }\end{array}$ \\
\hline
\end{tabular}

\section{Tabla 5}

Tercer momento: proposiciones fácticas, pruebas y peritos

Fuente: elaborado con base en Juzgado Cuarto Penal del Circuito Especializado de Conocimiento de Bogotá (2009). Sentencia 19 contra David Murcia-Guzmán, Proceso 110016000020080790 


\begin{tabular}{|c|c|c|}
\hline \multicolumn{3}{|c|}{ Cuarto momento } \\
\hline Proposición fáctica 18 & Pruebas & Peritos \\
\hline Las sociedades Grupo DMG S.A., DMG Grupo & Informe del presidente del Banco & Abogados Silvia Inés \\
\hline Holding S.A., Global Marketing Colombia S.A., & Agrario en el que advierte de una posible & Rueda-Buitrago, \\
\hline Bionat Labs S.A., Inversiones Sánchez Rivera y & captación de dinero por parte del Grupo & María Teresa Ariza- \\
\hline Cía. S.A., Productos Naturales DMG Ltda. y DMG & DMG S.A. & Montañés \\
\hline Publicidad y Mercadeo Colombia S.A. presentaron & Estados financieros de la sociedad Grupo & Contadores Luis \\
\hline inconsistencias e irregularidades en planos contable & DMG S.A., de 2005 y 2006 & Alberto Rosas, \\
\hline —doble contabilidad-, financiero, administrativo & Reglamento que la sociedad Grupo DMG & Evangelina Moreno, \\
\hline y jurídico, al tiempo que realizaron traslados de & S.A. fijó para utilización de tarjetas & Gladys Amorocho- \\
\hline grandes cantidades de dinero en efectivo & prepago & Chacón \\
\hline Proposición fáctica 23 & Pruebas & Peritos \\
\hline \multirow{6}{*}{$\begin{array}{l}\text { También se capitalizaron empresas existentes como } \\
\text { Inversiones Sánchez Rivera y Cía. S.A., que fueron } \\
\text { utilizadas como intermediarias para aparentar } \\
\text { circulación de dinero }\end{array}$} & Comprobantes de consignación & Perito Gladys \\
\hline & Recibos de caja & Amorocho-Chacón \\
\hline & Notas bancarias y consulta de saldos de & \\
\hline & cuenta & \\
\hline & Soportes contables & \\
\hline & Certificados de Cámara de Comercio & \\
\hline
\end{tabular}

\section{Proposición fáctica 26}

Todas estas operaciones fueron lideradas $y$ controladas por el señor David Eduardo Helmunt

Murcia-Guzmán

Tabla 6

Cuarto momento: proposiciones fácticas, pruebas y peritos

Fuente: elaborado con base en Juzgado Cuarto Penal del Circuito Especializado de Conocimiento de Bogotá (2009). Sentencia 19 contra David Murcia-Guzmán, Proceso 110016000020080790

En este escenario, le corresponde al contador público que actúa como perito en este tipo de ilícitos conocer la normatividad contable y fiscal; las operaciones fraudulentas se pueden detectar al identificar las cuentas y transacciones contables de mayor riesgo en cada modelo económico de negocio, manejando y explorando las diferentes alternativas que pueden ser usadas por los defraudadores.

\section{Lineamientos para el manejo de la prueba pericial contable en los delitos económicos y financieros bajo el sistema penal acusatorio}

Una vez se han analizado los requerimientos legales de la prueba pericial y se han estudiado las pruebas del caso objeto de estudio, a continuación, se presentan los lineamientos que el profesional de la contaduría pública requiere conocer cuando le corresponde actuar como perito ante los tribunales de la justicia:

En primera instancia, es importante señalar que la prueba pericial es solicitada en torno de un programa metodológico elaborado por el fiscal encargado de coordinar la investigación, que ordenará las actividades conducentes al esclarecimiento de los hechos (Art. 205 CPP).

Una vez es designado, el perito contable recibirá los elementos materiales probatorios (EMP) y la evidencia física (EF) objeto de análisis; en la mayoría de los casos, será necesario el diligencia- 
miento del registro de continuidad del elemento material de prueba o evidencia física, entre el custodio y el perito que la recibe para asegurar la cadena de custodia. Al perito le corresponde diligenciar la siguiente información

La fecha de izquierda a derecha indicando el día, mes y año en los cuales se realiza el traspaso del elemento materia de prueba o evidencia. El campo de hora se diligencia utilizando el formato militar y corresponde a la hora en que se hace el traslado y/o traspaso del elemento materia de prueba o evidencia. Los nombres y apellidos completos de la persona que recibe el elemento materia de prueba o evidencia física. El número de cédula de ciudadanía de quien recibe, entidad a la cual pertenece, calidad en la que actúa respecto del elemento (en este caso, como perito). El propósito del traspaso corresponde a: estudio o análisis (en este caso). En el campo de observaciones, quien recibe anota las inconsistencias que detecte. Esta anotación la debe hacer en presencia de quien le entrega y avala el registro con su firma y por último, el número del protocolo o informe en el cual se detallan los análisis practicados a dichas evidencias, sus resultados y las personas que intervinieron en el análisis y custodia (Fiscalía, 2014).

\section{Estudio de los elementos materiales} probatorios y de la evidencia física por parte del perito contable en los delitos

\section{económicos y financieros}

Como ya se expresó, los delitos económicos y financieros están tipificados en el Código Penal; en cada caso, el perito contable tendrá la fun- ción de evaluar el EMP y la EF que la policía judicial le facilite para su posterior evaluación:

Delitos contra el orden económico social

\begin{tabular}{ll}
\hline $\begin{array}{l}\text { Delitos contra el } \\
\text { orden económico }\end{array}$ & El acaparamiento, la especulación \\
social (Título X CP) & contras infracciones, delitos \\
& urbanización ilegal, contrabando \\
& y lavado de activos (Capítulos \\
& $\mathrm{I}-\mathrm{V})$. \\
\hline
\end{tabular}

El orden económico y social se ha concebido como regulación jurídica de la organización económica y de la intervención estatal. En palabras de algunos autores: "el orden económico va a constituir el objeto de protección del derecho penal económico, dado el interés del Estado en la conservación de su capacidad productiva para el cumplimiento de su tarea y en la conservación del orden legal de la economía, tanto en su conjunto como en sus ordenaciones parciales" (Pinzón-Sánchez \& Carrillo-Flórez, 1985, p. 89).

En este caso, el perito contable se enfrenta al análisis de EMP y EF de diferente tipo, preparados en algunas ocasiones bajo fórmulas novedosas y técnicas complejas que permiten a primera vista engañar los controles y desdibujar la realidad. Por esta razón, la preparación y el trabajo del perito en este tipo de ilícitos se convierten en garantía del orden económico y social.

\section{Delitos contra el patrimonio económico}

\begin{tabular}{ll}
\hline Delitos contra & Hurto, extorsión, estafa, fraude \\
el patrimonio & mediante cheque, del abuso \\
económico (Título & de confianza, defraudaciones, \\
VII CP) & $\begin{array}{l}\text { usurpación, daño en bien ajeno } \\
\text { (Capítulos I-IX). }\end{array}$ \\
\hline
\end{tabular}




\section{6 / VOL. 16/ NO. 42 / SEPTIEMBRE-DICIEMBRE 2015}

Anteriormente denominados delitos contra la propiedad, el estatuto vigente acoge el rubro de delitos contra el patrimonio económico, que reúne en un solo tipo punible el apoderamiento violento o sin violencia de cosas muebles ajenas (Barrera-Domínguez, 1997, p. 3).

En este tipo de ilícitos, el análisis patrimonial de las víctimas - sean personas naturales o jurídicas-y el de los infractores es seguramente un requerimiento para el perito contable.

\section{Delitos contra la administración pública}

\begin{tabular}{ll}
\hline $\begin{array}{l}\text { Delitos contra la } \\
\text { administración }\end{array}$ & Peculado, concusión, cohecho, \\
pública (Título XV & celebración indebida de \\
CP) & entratos, tráfico de influencias, \\
& prevaricato, abuso de autoridad, \\
& delitos contra los empleados \\
& oficiales (Capítulos I-X). \\
\hline
\end{tabular}

El delito se define como toda aquella conducta (acción u omisión) contraria al ordenamiento jurídico del país donde se produce. En este caso, los delitos contra la administración púbica consisten en que los funcionarios públicos emiten actos ilegales, abusan de la confianza depositada en ellos para apropiarse y usar determinados bienes que se les ha encargado. En este tipo de delitos, el perito contable manejará los EMP y la EF relacionada "con entidades donde se presenta la corrupción administrativa, fenómeno tan antiguo como el más primitivo de los sistemas de organización estatal" (PabónParra, 2005, p. 1203).

Ahora bien, en los delitos económicos y financieros, el perito contable se enfrenta a un EMP y a una EF documental, y el caso del DMG Grupo Holding S.A. confirma esta apreciación.
No obstante, la legalidad de los documentos se resolverá a partir de los dictámenes periciales.

Dentro de la prueba documental que manejan los peritos contables, según el artículo 424 del CPP, este profesional tendrá acceso a los textos manuscritos, mecanografiados o impresos. Al igual que el juez, el perito tendrá en cuenta al apreciar cada documento - según el artículo 432 del CPP-los siguientes criterios: (1) que no haya sido alterado en su forma ni en su contenido, (2) que permita obtener un conocimiento claro y preciso del hecho, declaración o a testación de verdad, que constituye su contenido y (3) que dicho contenido sea conforme con lo que ordinariamente ocurre.

De esta forma, según el sistema penal acusatorio, el perito contable participa en dos momentos muy bien definidos, en cualquier proceso judicial:

- Una primera participación en la fase de indagación en la que le corresponde entregar el informe pericial construido sobre la evidencia y el material probatorio que le fue proporcionado.

- Y una segunda intervención durante el juicio oral. Para la aceptación del informe pericial, es imprescindible que el perito se presente en el juicio para ser interrogado y contrainterrogado, como lo establecen los artículos 412 y 415 del CPP. Durante la intervención en el juicio, debe hacer claridad sobre los procedimientos y análisis realizados, y sobre toda aquella información documentada en el informe pericial, que sirva para determinar la certeza de algún hecho en particular para el caso, de forma clara para que pueda ser entendida por todos aquellos que asistan a la audiencia. 


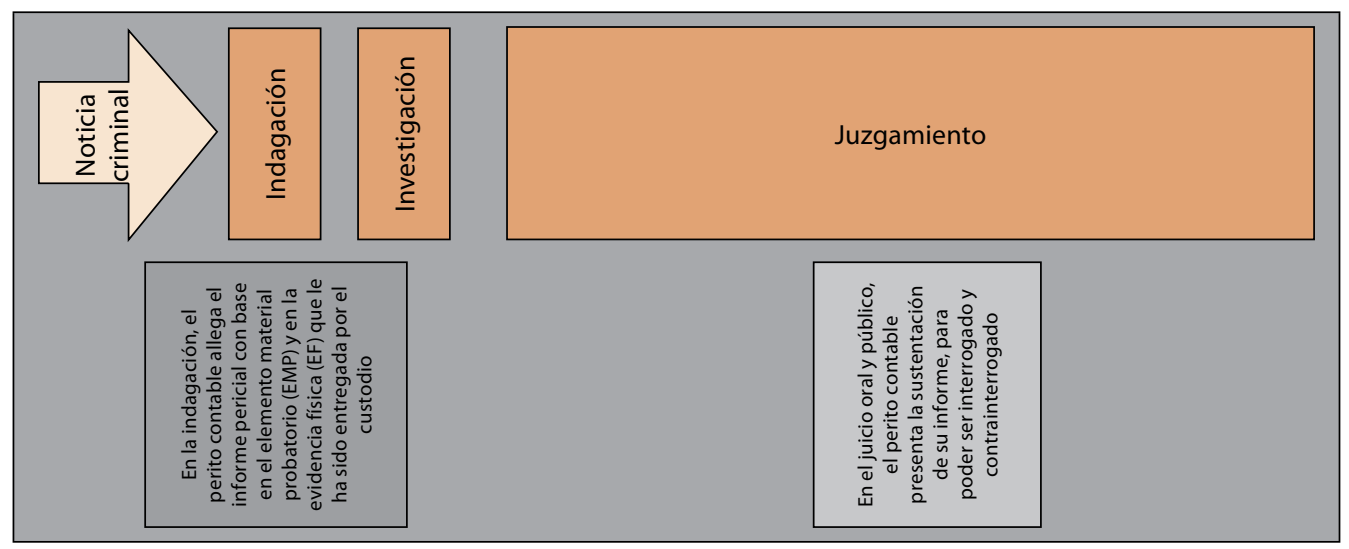

Figura 4

Participación del perito contable en el Sistema penal acusatorio en Colombia

Fuente: elaboración propia con base en el Código de Procedimiento Penal

\section{Informe pericial contable}

De conformidad con lo estipulado en los artículos 210, 255, 257, 261 y 275 del Código de Procedimiento Penal, el perito rinde su informe y declara bajo la gravedad de juramento, conforme al artículo 406 del mismo ordenamiento jurídico.

El perito debe presentar un informe resumido en que exprese la base de la opinión pedida por la parte que solicitó la práctica de la prueba, el cual debe ser puesto en conocimiento de las demás partes al menos con cinco (5) días de anticipación a la celebración de la audiencia pública; para que el informe sea admisible como evidencia, se requiere que el perito declare oralmente en el juicio.

Las partes solicitarán al juez que haga comparecer a los peritos al juicio oral y público, para ser interrogados y contrainterrogados en relación con los informes periciales que hubiesen rendido, o para que los rindan en la audiencia (Art. 412 CPP).

Para la elaboración del informe pericial por parte del perito, la Fiscalía General de la Nación ha establecido los siguientes requerimientos (Fiscalía, 2014):

\footnotetext{
Informe pericial

Objetivo de la diligencia

Descripción clara y precisa de los elementos materiales probatorios y evidencia física examinada

Descripción de los procedimientos técnicos empleados

Informe sobre el grado de aceptación por la comunidad técnico científica, de los procedimientos empleados

Instrumentos empleados y estado de estos al momento del peritaje o examen técnico científico (relacionándolos y

describiendo su estado al momento del examen)

Explicación del principio o principios técnicos y científicos aplicados (informe sobre el grado de aceptación por la comunidad científica)

Descripción clara y precisa de los procedimientos técnicos de su actividad técnico-científica

Interpretación de resultados
}

Tabla 7

Contenido del informe pericial

Fuente: Fiscalía General de la Nación (2014) 
Las partes podrán presentar informes de peritos de su confianza y solicitar que estos sean citados a interrogatorio en el juicio oral y público, acompañando certificación que acredite la idoneidad del perito (Art. $413 \mathrm{CPP}$ ).

Si el juez admite el informe presentado por la parte, en la audiencia preparatoria, inmediatamente ordenará citar al perito o peritos que lo suscriben, para que concurran a la audiencia del juicio oral y público con el fin de ser interrogados y contrainterrogados (Art. 414 CPP).

Los peritos, tanto los que hayan rendido informe, como los que solo serán interrogados y contrainterrogados en la audiencia del juicio oral y público, tendrán acceso a los elementos materiales probatorios y la evidencia física a que se refiere el informe pericial o a los que se hará referencia en el interrogatorio (Art. 416 $\mathrm{CPP})$. El perito deberá ser interrogado en relación con los siguientes aspectos (Art. 417 CPP):

Sobre los antecedentes que acrediten su conocimiento teórico sobre la ciencia, técnica o arte en que es experto.

- Sobre los antecedentes que acrediten su conocimiento en el uso de instrumentos o medios en los cuales es experto.

- Sobre los antecedentes que acrediten su conocimiento práctico en la ciencia, técnica, arte, oficio o afición aplicables.

- Sobre los principios científicos, técnicos o artísticos en los que fundamenta sus verificaciones o análisis y grado de aceptación.

- Sobre los métodos empleados en las investigaciones y análisis relativos al caso.

- Sobre si en sus exámenes o verificaciones utilizó técnicas de orientación, de probabilidad o de certeza.
- La corroboración o ratificación de la opinión pericial por otros expertos que declaran también en el mismo juicio, y

- Sobre temas similares a los anteriores.

El perito responderá de forma clara y precisa las preguntas que le formulen las partes. El perito tiene, en todo caso, derecho de consultar documentos, notas escritas y publicaciones con la finalidad de fundamentar y aclarar su respuesta.

\section{Instrucciones para contrainterrogar al perito}

El contrainterrogatorio del perito se cumplirá observando las siguientes instrucciones (Art. 418 CPP):

a. La finalidad del contrainterrogatorio es refutar, en todo o en parte, lo que el perito ha informado.

b. En el contrainterrogatorio se podrá utilizar cualquier argumento sustentado en principios, técnicas, métodos o recursos acreditados en divulgaciones técnico científicas calificadas, referentes a la materia de controversia.

Para apreciar la prueba pericial, en el juicio oral y público, se tendrá en cuenta la idoneidad técnico científica y moral del perito, la claridad y exactitud de sus respuestas, su comportamiento al responder, el grado de aceptación de los principios científicos, técnicos o artísticos en que se apoya el perito, los instrumentos utilizados y la consistencia del conjunto de respuestas (Art. $420 \mathrm{CPP}$ ). 


\section{Conclusiones}

Al contador público le corresponde actuar como perito en los procesos judiciales adelantados por delitos económicos y financieros, como profesional auxiliar de la justicia en los casos que señala la Ley, como perito expresamente designado para ello. La participación del perito contable en los procesos judiciales está sujeta al programa metodológico elaborado por el fiscal.

En el marco del Sistema Penal Acusatorio colombiano, al perito contable le corresponde actuar en dos momentos claramente definidos; en la etapa de indagación, al hacer entrega de su informe pericial elaborado con base en los elementos materiales probatorios y en las evidencias físicas entregadas por la policía judicial. Y en la etapa de juzgamiento, en especial en el juicio oral, cuando le corresponde sustentar su informe pericial y si se requiere, someterse al interrogatorio y contrainterrogatorio.

La prueba pericial contable es un medio probatorio determinante en la etapa de investigación en los casos de delitos económicos y financieros; su hallazgo y validez dependen de la experticia y el conocimiento del contador público respecto de la materia en cuestión.

El caso del DMG Grupo Holding S.A. es un referente valedero para determinar la importancia de la prueba pericial contable en los delitos económicos y financieros, y la relevancia de la actuación del contador público como perito contable auxiliar de la justicia en este tipo de ilícitos.

El contador público, en su calidad de perito auxiliar de la justicia, debe conocer los lineamientos requeridos por la Fiscalía General de la Nación en la elaboración del dictamen pe- ricial, el cual debe contener como mínimo: el objetivo de la diligencia; la descripción clara y precisa de los elementos materiales probatorios y la evidencia física examinada; la descripción de los procedimientos técnicos empleados; el informe sobre el grado de aceptación por la comunidad técnico científica de los procedimientos empleados; los instrumentos empleados y el estado de estos al momento del peritaje o examen técnico-científico (relacionándolos y describiendo su estado al momento del examen); la explicación del principio o principios técnicos y científicos aplicados (informe sobre el grado de aceptación por la comunidad científica); la descripción clara y precisa de los procedimientos técnicos de su actividad técnico-científica y, por último, la interpretación de los resultados.

\section{Referencias}

Avella-Franco, Pedro Oriol (2007). Estructura del proceso penal acusatorio. Bogotá: Fiscalía General de la Nación, Escuela de Estudios e Investigaciones Criminalísticas y Ciencias Forenses. Disponible en: http://www.fiscalia.gov. co/en/wp-content/uploads/2012/01/ EstructuradelProcesoPenalAcusatorio.pdf Barrera-Domínguez, Humberto (1997). Delitos contra el patrimonio económico. Bogotá: Ediciones Librería del Profesional.

Bedoya-Sierra, Luis Fernando (2008). La prueba en el proceso penal colombiano. Bogotá: Fiscalía General de la Nación, Escuela de Estudios e Investigaciones Criminalísticas y Ciencias Forenses. 
Disponible en: http://www.fiscalia.gov.co/ colombia/wp-content/uploads/2012/01/ LaPruebaenelProcesoPenalColombiano.pdf Borja-Niño, Manuel Antonio (2000). La prueba en el derecho colombiano. Tomo III, Declaración de parte, confesión y testimonio. Bucaramanga: SIC Editorial Limitada.

Borja-Niño, Manuel Antonio (2003). La prueba en el derecho colombiano, Tomo IV, La prueba documental, la prueba pericial, la inspección y la prueba por indicios. Bucaramanga: Editorial Universidad Autónoma de Bucaramanga, UNAB, Colección Letra Cátedra.

Cano-Castaño, Miguel Antonio (2000). Prácticas contables para detectar el lavado de dinero. Bogotá: G\&D Impresores.

Climent-Durán, Carlos (1999). La prueba penal. Valencia: Tirant lo Blanch.

Colombia (2002). Acto Legislativo 03 de 2002, por el cual se reforma la Constitución Nacional. Diario Oficial, 45.040, 20 de diciembre de 2002. Disponible en: http://www. secretariasenado.gov.co/senado/basedoc/ acto_legislativo_03_2002.html

Colombia (1991). Constitución Política. Gaceta Constitucional, 116, 20 de julio de 1991. Disponible en: http://www. secretariasenado.gov.co/senado/basedoc/ constitucion_politica_1991.html

Colombia (1970). Decreto 1400 de 1970, por el cual se expide el Código de Procedimiento Civil. Diario Oficial, 33.150, 21 de septiembre de 1970. Disponible en: http:// www.secretariasenado.gov.co/senado/ basedoc/codigo_procedimiento_civil.html Colombia (1993). Decreto 2649 de 1993, por el cual se reglamenta la Contabilidad en Ge- neral y se expiden los principios o normas de contabilidad generalmente aceptados en Colombia. Diario Oficial, 41.156, 29 de diciembre de 1993.

Colombia (1993). Decreto 2650 de 1993, por el cual se modifica el Plan Único de Cuentas para Comerciantes. Diario Oficial, 41.156, 29 de diciembre de 1993. Disponible en: http://incp.org.co/Site/2012/ legislativa/2650.pdf

Colombia (1990). Ley 43 de 1990, por la cual se adiciona la Ley 145 de 1960, reglamentaria de la profesión de contador público y se dictan otras disposiciones. Diario Oficial, 39.602, 13 de diciembre de 1990. Disponible en: https:/www.cancilleria.gov. co/sites/default/files/Normograma/docs/ ley_0043_1990.htm

Colombia (2000). Ley 599 de 2000, por la cual se expide el Código Penal. Diario Oficial, 44.097, 24 de julio de 2000. Disponible en: http://www.secretariasenado.gov.co/senado/ basedoc/ley_0599_2000.html

Colombia (2004). Ley 906 de 2004, por la cual se expide el Código de Procedimiento Penal. Diario Oficial, 45.657, 31 de agosto de 2004. Disponible en: http://www. secretariasenado.gov.co/senado/basedoc/ ley_09060_204a.html

Colombia, Corte Constitucional (2011). Sentencia T-288-11, 14 de abril de 2011. Magistrado ponente Jorge Ignacio Pretelt-Chaljub. Disponible en: http:// www.corteconstitucional.gov.co/ RELATORIA/2011/T-288-11.htm Comisión Intersectorial para el Seguimiento de Sistema Penal Acusatorio, CISPA (2011). 
Balance de la legislatura 2010-2011 en materia penal. Bogotá: Comisión Intersectorial para el Seguimiento de Sistema Penal Acusatorio, CISPA. Disponible en: http:// www.cispa.gov.co/index.php?option $=\mathrm{com}_{-}$ docman\&task $=$ cat_view\&gid $=22 \&$ limit $=2$ 0\&limitstart $=5 \&$ order $=$ hits\&dir $=$ DESC\&I temid $=34$

Fiscalía General de la Nación (2003). Resolución 2869 de 2003, por medio de la cual se adopta el Manual de procedimientos del sistema de cadena de custodia, 29 de diciembre de 2003. Disponible en: http:// icbf.gov.co/cargues/avance/docs/resolucion_ fiscalia_2869_2003.htm

Fiscalía General de la Nación (2009). Prueba pericial. Bogotá: Fiscalía General de la Nación.

Fiscalía General de la Nación (2014). Formato informe investigador de laboratorio. Bogotá: Fiscalía General de la Nación.

Fiscalía General de la Nación (2014). Formato Cadena de Custodia. Bogotá: Fiscalía General de la Nación.

Fiscalía General de la Nación, Consejo Nacional de Policía Judicial (s.f.). Manual Único de Policía Judicial. Bogotá: Fiscalía General de la Nación, Consejo Nacional de Policía Judicial. Disponible en: http://www. dmsjuridica.com/CODIGOS/CODIGOS/ NUEVO_COD_PROCEDIMIENTO_ PENAL/MANUAL\%20DE\%20POLICIA/ manualPolicia.pdf

Juzgado Cuarto Penal del Circuito Especializado de Conocimiento de Bogotá (2009). Sentencia 19 contra David Murcia-Guzmán, Proceso 110016000020080790.
Lessona, Carlo (1964). Teoría general de la prueba en Derecho Civil o exposición comparada de los principios de la prueba en materia civil $y$ de sus diversas aplicaciones en Italia, Francia, Alemania, etc. $4^{\mathrm{a}}$ ed. Madrid: Instituto Editorial Reus S.A.

Morales-Rodríguez, Mary Luz (2000). Manual para la práctica de autopsias médico-legales. Bogotá: Instituto Nacional de Medicina Legal y Ciencias Forenses.

Nieva-Fenoll, Jordi (2010). La valoración de la prueba. Madrid: Marcial Pons Ediciones Jurídicas y Sociales S.A.

Pabón-Parra, Pedro Alfonso (2005). Manual de derecho penal. Bogotá: Ediciones Doctrina y Ley Ltda.

Parra-Quijano, Jairo (1996). Tratado de la prueba judicial, la prueba pericial. Bogotá: Ediciones Librería del Profesional.

Pinzón-Sánchez, Jorge \& Carrillo-Flórez, Fernando (1985). Sector financiero y delincuencia económica. Bogotá: Temis.

Restrepo-Medina, Manuel (2005). El nuevo sistema penal acusatorio. Bogotá: Intermedio Editores.

Rocha-Alvira, Antonio (1967). De la prueba en derecho. Bucaramanga: Lerner Ediciones.

Suárez-Hernández, Daniel (1997). De la peritación o la prueba por peritos. Madrid: Revista de Derecho Privado.

Varela, Armando Casimiro (1990). Valoración de la prueba. Buenos Aires: Editorial Astrea. Vargas-Vargas, Pedro Pablo \& Londoño-Herrera, Taylor (2005). Las pruebas en el sistema penal acusatorio colombiano: en 276 preguntas con sus respuestas y notas. Bogotá: Ediciones Doctrina y Ley Ltda. 


\section{2 / VOL. 16 / NO. 42 / SEPTIEMBRE-DICIEMBRE 2015}

- Fecha de recepción: 25 de agosto de 2015

- Fecha de aceptación: 20 de noviembre de 2015

- Disponible en línea: 15 de mayo de 2016

\section{Para citar este artículo}

Ramírez, M.; Robayo, N. \& Parra, L. (2015). La prueba pericial contable especializada en los delitos económicos y financieros: análisis del caso DMG. Cuadernos de Contabilidad, 16(42), 689-712. http://dx.doi. org/10.11144/Javeriana.cc16-42.ppce 